\title{
Research on Neutral Point Grounding Technology for Marine High Voltage Power System
}

\author{
Zhiliang $\mathrm{Wu} *$ \\ Marine Eng. College \\ Dalian Maritime University \\ Dalian, China \\ wzl001@dl.cn \\ Yubin Yao \\ Marine Eng. College \\ Dalian Maritime University \\ Dalian, China \\ yaoyubin@dlmu.edu.cn
}

\author{
Dan Wang \\ Marine Eng. College \\ Dalian Maritime University \\ Dalian, China
}

\begin{abstract}
The type of neutral point grounding is a key technology and hot point for marine high voltage power system. In order to study the special type of neutral point grounding for marine high voltage power systems, the feature of various types of neutral point grounding for general marine power systems was discussed. A mathematical model of single phase grounding current for any different neutral point grounding method was de veloped by using Kirchhoff's Laws. A general formula of single phase grounding current for any different neutral point grounding method was deduced, and then a formula of single phase grounding current for marine high voltage power system was deduced, too. The selection and calculation basis for designing high resistor was given. The reason why high resistance grounding should be adopted for marine high voltage power system was summarized, and thus a sound theory and practice basis is provided for further research on marine high voltage power systems.
\end{abstract}

Keywords- Ship; Marine Power System; Neutral Point; High Resistance Grounding; High Voltage

\section{INTRODUCTION}

With the continuous improvement of ship on large-size and automation level, the capacity of the marine power system is increasing sharply, so the traditional marine low voltage power system has been unable to satisfy the requirements of marine high power system. It is necessary to select marine high voltage power system for marine high power system, such as large passenger liner, oil tanker, electric propulsion ship, some special working ship and so on[1] .

The voltage level of marine high voltage power system is limited between $1 \mathrm{KV}$ and $15 \mathrm{KV}$, according to the Rules for Classification of Sea-going Steel Ships (2012). There is a big difference between marine low voltage power system and high voltage power system on safety protection devices, the type of neutral point grounding, transformer, distribution methods, the structure and processing ways of cable socket. There is different structure of function in all panel of high voltage switchboard, such as isolated switch room, cable room, low voltage chamber, and so on. The operation requirements of interlocking protection are known as the "five-prevention measures" inside the panel. In order to prevent internal fault, high-voltage generator is equipped with longitudinal differential protection and the excitation device of high-voltage generator has the performance of de-excitation which can demagnetize generator after circuit breaker tripping. In particular, marine high voltage power system which always adopts neutral point grounding system is essentially different from low voltage power system which employs generally neutral point insulation system. The type of grounding method of neutral point is the key technology to be solved in the marine high voltage power system. From the view of domestic and foreign application, marine high voltage power system commonly adopts high resistance grounding method at the moment[2-3] .

\section{NEUTRAL POINT OPERATION MODE OF THE POWER} SYSTEM

Neutral point operation mode of the power system is what grounding method neutral point of power or transformer adopts. [4-5]

\section{A. The type of neutral point operation mode}

Neutral point operation can be commonly classified as the following types:

a) Neutral point un-earth: Namely isolated neutral point;

b) Neutral point directly earth: Neutral point is connected to grounding device directly.

c) Neutral point earth with Petersen-coil: Neutral point is connected to grounding device by means of reactor (Petersen-coil). 
d) Neutral point earth with resistance: Neutral point is connected to grounding device by resis tance..

\section{B. The analysis of neutral point grounding way}

Neutral point grounding way of power system is a comprehensive technical problem, so the following factors must be considered: the security, continuity and reliability of power system; the coordination between over-voltage protection and insulation technology; the constituent of rely protection and the method of circuit breaker tripping; the construction of electric distribution network and circuit; the personal and equipment safety, and so on.

\section{1) Neutral point un-earth way}

Neutral point un-earth way is safe and reliable, because it is insulated from the earth, and don't affect the symmetry of voltage among the three phases when earth fault occurs in power system, and what's more, it can continue to run with single-phase earth fault for 2 hours, so the continuity of power supply is good. Single-phase grounding current is determined by grounding capacitance current in the neutral point un-earth power system. Earth fault current is very small, and transient fault always can be automatically eliminated, because single-phase earth capacity of power transmission line is relatively small. Due to small earth current, the interference to communication circuit is also small. The disadvantage of neutral point un-earth way is that the other two phase voltage may rise to $\sqrt{3}$ times, when one phase is grounded, which makes the point where insulation is weak breakdown, and causes the two phase grounding short circuit.

The single-phase grounding capacitive current is very big in general in the high voltage and long-distance transmission lines, and the capacitive current leads voltage by $90^{\circ}$. The voltage on the point of fault reaches its peak when the capacitive current on the point of fault passes zero and blows out arc. If the capacitive current is too large and the air is ionized seriously, it will break down the point of failure again, and the reigniting is difficult to avoid sometimes. The reigniting and extinguishing of arc easily, so-called intermittent arc occurs on the point of grounding, which can cause high-frequency oscillation, form the intermittent arc over-voltage, may break down the insulation of equipment, and cause a short circuit fault. In order to avoid intermittent arc, the grounding current of $3 \sim 10 \mathrm{KV}$ power grid is less then $30 \mathrm{~A}$, and the grounding current of more than $35 \mathrm{KV}$ power grid is not more than 10A. Therefore, the neutral point un-earth mode is not suitable for the high voltage and long-distance transmis sion lines.

Neutral point un-earth way is generally adopted for traditional marine low voltage power system.

\section{2) Neutral point directly earth way}

The advantage of neutral point directly earth way is that the other two phase voltage don't rise, and there is no over-voltage caused by intermittent arc, when one phase grounds, so the insulation level of whole power system can be reduced, which is important to reduce the cost of ultrahigh voltage grid above $110 \mathrm{kV}$. Therefore, the power grid more than $110 \mathrm{kV}$ widely adopts neutral point directly earth. Besides, short circuit current is so high that protection relay operates quickly and accurately, and the reliability of protection is improved. However, the large capacity switch and equipment needs to be chosen because of big short circuit current, which can cause some deficiencies, such as unstable system and strong interference with communication line.

\section{3) Neutral point earth with Petersen-coil way}

The inductive current of reactor compensates the capacitive current of power grid in the way of neutral point earth with Petersen-coil, which can reduce the grounding current. If the inductive current is equal to the capacitive current, namely full compensation, it is very advantageous to extinguish grounding arc. However, full compensation is impossible because of the line resistance, the grounding resistance, the leaking resistance, the active power loss of Petersen-coil and transformer, etc, which generate a little residual current on the point of fault. If the three phase distributed capacitors between ground isn't symmetrical during normal operation, or one phase is open circuited, the Peters en-coil and the distributed capacitors are likely to resonate serially, which may cause the dangerous high potential on the neutral point of the power system. Therefore, Petersen-coil is generally used for overcompensation operation, in other words, the inductor current is greater than capacitive current, which also is a disadvantage of the neutral point earth with Petersen-coil. In addition, the system is more complex, and the investment in equipment is larger.

4) Neutral point earth with high resistance way [6-7]

The most outstanding characteristic of Neutral point earth with high resistance is that the power system can continue to run with fault for 2 hours, and also can trip quickly or periodically by choosing.

To limit the transient over-voltage caused by arc grounding fault, the design of earth with high resistance should the principle that the grounding resistance isn't more than total distributed capacitive reactance of each phase.

The purpose of earth with resistance is injecting resistance current in the power system, which can make the fault current have the nature of resistor-condenser, reduce the phase angle difference between fault current and voltage, and reduce the reigniting rate of grounding current after passing zero and blowing out arc. When the resistance current is large enough, the reigniting will not occurs, thus, it prevents intermittent arc over-voltage of grounding and resonance; Neutral point earth with high resistance can also limit the single-phase grounding fault current in power system, what's more, if the resistorcondenser current is greater than the capacitive current, the sensitivity of zero sequence protection will be improved, acting on the breaker to trip, meeting the requirements of relay protection.

Modern marine high voltage power system generally adopts neutral point earth with high resistance. [1]

\section{THE CALCULATION OF SINGLE PHASE GROUNDING CURRENT FOR DIFFERENT TYPES OF NEUTRAL POINT GROUNDING METHOD}

In order to discuss the single phase grounding current for various earth methods in power system, researchers can suppose the neutral point earth by paralleling resistors and inductors, the distributed capacitance to ground of every phase is $\mathrm{C}$ in power system. Phase $\mathrm{A}$ is regarded as a referenced one, when earth fault happens, there is a 
grounding resistance $\mathrm{Rd}$ around grounding point, $\mathrm{RN}$ is neutral point grounding resistance, $\mathrm{LN}$ is neutral point grounding inductance, as the Fig. 1 shows.

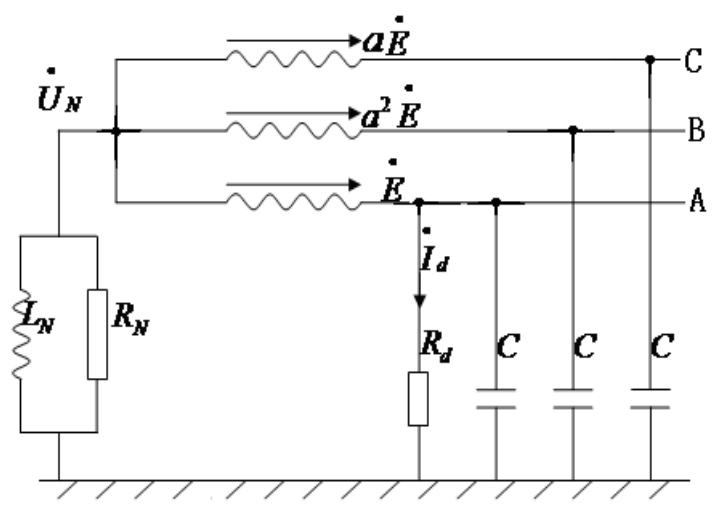

Figure 1. The single phase grounding diagram of power system

Supposing the voltage of three phases is balanced before earth happened, after that, there will be a voltage Un between neutral point and ground, this moment the three phase voltages referring to ground are:

$$
\left\{\begin{array}{c}
\dot{U}_{A}=\dot{U}_{N}+\dot{E} \\
\dot{U}_{B}=\dot{U}_{N}+a^{2} \dot{E} \\
\dot{U}_{C}=\dot{U}_{N}+a \dot{E}
\end{array}\right.
$$

Where, $a=\mathrm{e}^{\mathrm{j} 120^{\circ}}, a^{2}=\mathrm{e}^{\mathrm{j} 240^{\circ}}$.

According to Kirchhoff's Current Laws, take the ground as a node, and then the current relation that passes through the ground is:

$$
\begin{aligned}
& \dot{U}_{N}\left(g_{N}-\mathrm{j} b_{N}\right)+\left(\dot{U}_{N}+\dot{E}\right)\left(g_{d}+\mathrm{j} \omega C\right)+ \\
& \left(\dot{U}_{N}+a^{2} \dot{E}\right) \mathrm{j} \omega C+\left(\dot{U}_{N}+a \dot{E}\right) \mathrm{j} \omega C=0
\end{aligned}
$$

Where, $b_{N}=1 /\left(\omega L_{N}\right)$ is the neutral point grounding susceptance, $g_{N}=1 / R_{N}$ is the neutral point grounding conductance, $g_{d}=1 / R_{d}$ is the earth point conductance, therefore, the neutral point voltage referring to ground:

$$
\dot{U}_{N}=\frac{-\dot{E} g_{d}}{\left(g_{d}+g_{N}\right)+\left(\mathrm{j} 3 \omega C-\mathrm{j} b_{N}\right)}
$$

The current that pass through the earth point:

$$
\dot{I}_{d}=\left(\dot{U}_{N}+\dot{E}\right) g_{d}=\dot{E} g_{d} \frac{g_{N}+\mathrm{j} 3 \omega C-\mathrm{j} b_{N}}{g_{N}+g_{d}+\mathrm{j} 3 \omega C-\mathrm{j} b_{N}}
$$

Equation (4) is commonly used to calculate earth current for different grounding methods. It will be discussed in following several parts respectively.

(1) When single phase metallic earth happens in the way that neutral point disconnect to earth, $g_{d}=\infty, g_{N}=0$, $b_{N}=0$, the grounding current which passes the earth point: $\dot{I}_{d}=\dot{E} \mathrm{j} 3 \omega C$, it is only composed of distributed capacitive current, and this current leads $90^{\circ}$ to the voltage of the earth phase.

(2) When single phase metallic earth happens in the way that neutral point grounding with Petersen-coil, $g_{d}=\infty$, $g_{N}=0$, the current which passes the earth point: $\dot{I}_{d}=\mathrm{j}\left(3 \omega C-1 /\left(\omega L_{N}\right)\right) \dot{E}$. The grounding current includes inductive and capacitive current, and the inductive current of reactor is utilized to compensate capacitive current of power net, which can enormously decrease the grounding current. If researchers reasonably choose Petersen-coil and make $3 \omega C=1 /\left(\omega L_{N}\right)$, that's to say $\dot{I}_{d}=0$, we can realize compete compensation, the compete compensation is very useful to extinguish electric-arc.

(3) When single phase metallic earth happens in the way that neutral point grounding with high resistance, $g_{d}=$ $\infty, b_{N}=0$, the current which passes the earth point: $\dot{I}_{d}=\dot{E}\left(g_{N}+\mathrm{j} 3 \omega C\right)$, the grounding current consists of capacitive current and resistive current, which makes earth fault current to be capacitive, it can reduce the phase angle between the earth fault current and it is voltage. Obviously, the resistive current is relative to neutral grounding resistance $\mathrm{RN}$, the more $\mathrm{RN}$ is, the lower resistive current is, and vice versa.

\section{THE ANALYSIS OF NEUTRAL POINT GROUNDING WITH HIGH RESIST ANCE FOR MARINE HIGH VOLT AGE POWER SYSTEM}

Owing to the extremely high demand of insulation technology for marine high voltage power system, and considering the cost of insulation for high voltage power system, human safety .etc, especially the particularity of marine high voltage power system, ship grounding is actually connect to hull, and the hull itself is a good conductor, it may not only endanger human safety easily, but also damage low-voltage devices if there is a closed circuit between the high voltage system and low voltage system. In this case, the requirements of neutral point grounding technology for marine high voltage power system are not a bit high, and it is very complex to deal with, therefore, the study on this technology attracts a wide attention.

\section{A. The calculation of grounding current for marine high voltage power system}

It is popular to adopt high resistance grounding of neutral point for marine high voltage power system, generally the resistance is bigger than $500 \Omega$.

The principle for the selective design of resistive current $I_{R}$ :

(1) The resistive current of earth point is not lower than 1 to 1.5 times capacitive current as required, that's to say $I_{R} \geq(1 \sim 1.5) I_{C}$, to make sure that intermittent arc-grounding over-voltage will not happen. Such being the case, the over-voltage will not exceed 2.6 times phase voltage in general, and it is also the over-voltage which generator can endure. The standard of withstanding voltage is 1.5 times rated line voltage for common marine alternating current generator, the same as 2.6 times phase voltage. In that case, the grounding over-voltage which is lower than 2.6 times phase voltage is seemed to be a safe one. In other words, 
the over-voltage of marine alternating current generator is not advisable to be more than 2.6 times phase voltage.

$I_{C}$ is total capacitive current of power system, there will appear capacitance between all high voltage cable and ground, and this type of capacitance is called distributed capacitance. The capacitive current is sum of leakage current which produced by distributed capacitance, so it is relative to the specification and length of cable, researchers can get know the capacitive current or capacitance per unit length from related manuals, and then multiply it by actual length of cable in specific ship to calculate the total capacitive current.

The resis tive current of earth point:

$$
I_{R}=U_{N} / R_{N}=U_{e} /\left(\sqrt{3} R_{N}\right)
$$

Where, $U_{N}$ is the voltage between neutral point and ground, $U_{e}$ is rated line voltage.

The total capacitive current of power system:

$$
I_{C}=3 \omega C U_{e} / \sqrt{3}
$$

(2) $I_{d} \geq 3 \mathrm{~A}$, to ensure the sensitivity of grounding protection for generator.

The insertion of $R_{N}$ will increase the single-phase grounding fault current by $\sqrt{2}$ times or more, and change to be resistive and capacitive coexisted current from pure capacitive current, the total single-phase grounding fault current $I_{d}=\sqrt{I_{R}^{2}+I_{C}^{2}}$.

(3) $I_{d} \leq(10 \sim 15)$ A, to reduce the burning damage to the core of generator when the stator winding appears singlephase grounding fault in generator.

(4) According to the Rules for Classification of Seagoing Steel Ships(2006): when power system adopts neutral point grounding, the grounding fault current should never more than full-load current of most one generator in the switchboard or the subsection of switchboard, and not lower than 3 times of the minimum acting current of the grounding fault protection device:

$$
I \leq I_{d} / 3
$$

\section{B. The selection and calculation of the resistance of grounding reactor for marine high voltage power system}

The selection of reactor should according to the technology condition, such as nominal voltage, the most running voltage, frequency, current, resistance value, level of protection, type of cooling, the flowing time, the insulation level, what's more, researchers should check it with environmental condition, for examp le, environmental temperature, relative humidity. The following parts will put key point on the selection and calculation of reactor. The selection and calculation of resistance of reactor RN depend on the capacitive current IC and the choice of resis tive current IR, according to $I_{R} \geq I_{C}$,

$$
\text { And then: } U_{e} /\left(\sqrt{3} R_{N}\right) \geq 3 \omega C U_{e} / \sqrt{3} \text {, So, }
$$

$$
R_{N} \leq 1 /(3 \omega C)
$$

Take safe margin into account: generally $I_{R}=1.5 I_{C}$, So,

$$
R_{N}=1 /(4.5 \omega C)=1 /(9 \pi f C)
$$

When the electric arc is connected to the ground, in the process of arc lighting and extinguishing, the marine high voltage power system will accumulate redundant electric charge, and intensify the oscillation, and then produce a high over-voltage. If researchers can dissipate the charge by the neutral point grounding reactor before a period that electric arc relights from crushing out (about a half fundamental frequency cycle), and the over-voltage will greatly reduces. The capacitor between high-voltage cable and ground for marine high voltage power system discharges to neutral point grounding resistance $\mathrm{RN}$ follows the exponential function principle $f(t)=\mathrm{e}^{-t / \mathrm{T}}$, if $R_{N}=1 /(3 \omega C)$, the time constant of discharging $T=$ $3 R_{N} C=1 / \omega=1 /(2 \pi f)$, if it is equal to a half fundamental frequency cycle, in other words, when $t=1 /(2 f), f(t)=\mathrm{e}^{-t / \mathrm{T}}$ $=\mathrm{e}^{-\pi}=0.04$, this indicates in the half fundamental frequency cycle, the charge of the high-voltage cable reduce to 0.04 from 1, obviously, $96 \%$ have been discharged, so there will not appears a very high overvoltage any longer in general.

If $R_{N}=1 /(4.5 \omega C)=1 /(9 \pi f C)$, the time constant of discharging $T=3 R_{N} C=1 /(3 \pi f)$, when $t=1 /(2 f), f(t)=\mathrm{e}^{-t / \mathrm{T}}$ $=\mathrm{e}^{-1.5 \pi}=0.009$, this indicates in the half fundamental frequency cycle, the charge of the high-voltage cable reduce to 0.009 from 1 , more than $99 \%$ electric charge have been discharged, so there will not appear a high overvoltage any more. [8-10]

\section{CONCLUSIONS}

With the constantly increase of capacity of marine power system, high voltage power system has been a necessary choice for huge marine power system. Marine high voltage power system is a new area in domestic navigation, there are so much different in technology, maintenance, management mode comparing to traditional low power system, recently, it is in the beginning step for domestic marine high voltage power system. Especially, with the spreading and using of marine high voltage power system, the technology of neutral point grounding has attracted great attention of ship designers. The type of neutral point grounding is a key technology and hot point for marine high voltage power system.

\section{REFERENCES}

[1] Wu zhiliang. Marine power station. Dalian: the press of Dalian Maritime University, 2012

[2] Zhang Hairong ,Zhu Di,Xu Danzheng. Design of the intermediate voltage power system for the $4000 \mathrm{t}$ crane ship. SH IP\&BOAT, 2005(6): 27-30.

[3] Wang Liangxiu, Tang Shiqing, Li Dongli. A Research on Neutral Grounding Method of on-board Power System. MARINE ELECTRIC \& ELECT RONIC ENGINEERING, 2006, 26(5): 4144.

[4] Nelson JP, Burns D, Seitz R. The grounding of marine power systems problems and solutions. Petroleum and Chemical Industry Technical Conference, 2004. Page(s):151 - 161. 
[5] Tang zhiping. Engineering of power and distribution. Beijing: Publishing House of Elect ronics Industry, 2006

[6] Nie Hong-zhan, Zhao Fu-wei, Yuan Gui-dong. Research on Neutral Point Grounding via Resistance for $66 \mathrm{kV}$ Distribution Net work. Power System Technology, 2007, 31(14): 74-78.

[7] Tang Xiang, Mu Long-hua. Study on 3.3KV Power System with Neutral Point via Resistance Grounding. High Voltage Apparatus, 2005(6):452-455.

[8] Wang Peng.Neutralpoint earthed modes for ship intermediate voltage power system. SHIP \& BOAT, 2007 (3): 49- 54
[9] Caiqin Sun, Chen Guo, Chengjun Shi. Modeling and Simulating to Large Intelligent Marine Power Station System. Intelligent Control and Automation, 2006. The Sixth World Congress 2006(2): 6128 6132.

[10] Duncan BK, Bailey BG. Protection metering monitoring and control of medium voltage power systems. Industrial and Commercial Power Systems, 2003. 2003 IEEE Technical Conference Page(s):121 - 128. 